\title{
Role of Mesenchymal Cell Death in Lung Remodeling after Injury
}

Vitaly A. Polunovsky, Baruch Chen, * Craig Henke, Dale Snover, Christine Wendt, David H. Ingbar, and Peter B. Bitterman* Departments of Medicine and Laboratory Medicine and Pathology, University of Minnesota Medical School, Minneapolis, Minnesota 55455

\begin{abstract}
Repair after acute lung injury requires elimination of granulation tissue from the alveolar airspace. We hypothesized that during lung repair, signals capable of inducing the death of the two principal cellular elements of granulation tissue, fibroblasts and endothelial cells, would be present at the air-lung interface. Bronchoalveolar lavage fluid obtained from patients during lung repair induced both fibroblast and endothelial cell death, while fluid obtained at the time of injury or from patient controls did not. The mode of cell death for endothelial cells was apoptosis. Fibroblast death, while morphologically distinct from necrosis, also differed from typical apoptosis. Only proliferating cells were susceptible to the bioactivities in lavage fluid, which were trypsin sensitive and lipid insoluble. Histological examination of lung tissue from patients after lung injury revealed evidence of apoptotic cells within airspace granulation tissue. Our results suggest that cell death induced by peptide(s) present at the air-lung interface may participate in the remodeling process that accompanies tissue repair after injury. (J. Clin. Invest. 1993. 92:388-397.) Key words: apoptosis • granulation tissue • fibroblasts • endothelial cells • cell death
\end{abstract}

\section{Introduction}

Understanding how the size of lung cell populations is controlled as the gas exchange apparatus is repaired after acute lung injury represents a fundamental domain of knowledge for improvements in patient care to be achieved. Acute lung injury at present is both a common and lethal condition. For example, each year in the United States, 150,000 patients are treated for acute lung injury with $>50 \%$ of afflicted patients dying ( 1 , 2 ). The disease process begins with an explosive inflammatory response in the alveolar wall after exposure to noxious environmental or endogenous agents $(3,4)$. In the aftermath of the resultant tissue destruction, a fibroproliferative response ensues, leading to extensive granulation of the alveolar airspace (5-7). Morphologically, this intraalveolar granulation tissue is comprised mainly of mesenchymal cells, fibroblasts and endothelial cells, as well as their connective tissue products. In patients who die after lung injury, airspace granulation persists

Address correspondence Peter B. Bitterman, M.D., Division of Pulmonary and Critical Care Medicine, UMHC Box 132, 420 Delaware St. SE, Minneapolis, MN 55455. Baruch Chen's current address is Pulmonary Medicine and Critical Care, Sapir Medical Center, Meir General Hospital, Tel-Aviv University Medical School, Kfar Saba 44281, Israel.

Received for publication 18 December 1991 and in revised form 15 January 1993.

J. Clin. Invest.

(c) The American Society for Clinical Investigation, Inc.

$0021-9738 / 93 / 07 / 388 / 10 \quad \$ 2.00$

Volume 92, July 1993, 388-397 and progresses. In survivors, there is apparent resolution of the granulation tissue with concomitant reconstitution of the gas exchange apparatus (8).

Considerable attention has been focused on the identifiable signals that promote a fibroproliferative response. Studies in acute lung injury have identified a set of candidate profibrotic factors including two unique forms of platelet-derived growth factor, a novel angiogenesis factor, and established isoforms of basic fibroblast growth factor $(9,10)$. However, a key question arises in the natural history of this disorder: What happens to the intraalveolar mesenchymal cells in those patients who survive and are able to resolve their fibroproliferative response? Despite its pivotal clinical role, the biological processes involved in the prompt and orderly elimination of the intraalveolar mesenchymal cells remain undefined. Reexamination of data obtained in an effort to identify profibrotic signals present after acute lung injury led us to consider the possibility that mesenchymal cell death was occurring. Our experiments indicate that peptide(s) capable of inducing endothelial cell apoptosis, and a similar but distinct mode of death in lung fibroblasts are present at the air lung interface in patients recovering from acute lung injury.

\section{Methods}

\section{Study population}

Bronchoalveolar lavage fluid was obtained from patients during fiberoptic bronchoscopy as previously described (9). Our protocol was reviewed and approved by the University of Minnesota Committee for the Use of Human Subjects in Research. After obtaining informed consent, patients meeting established criteria for severe acute lung injury (adult respiratory distress syndrome) (9) were studied at two points in time during the course of their illness: $(a)$ early, during the interval of acute alveolar inflammation ( $\leq 3 \mathrm{~d}$ after the onset of lung injury); or $(b)$ late, during the phase of lung repair ( $>10 \mathrm{~d}$ after the onset of lung injury). The control group consisted of outpatients undergoing a clinically indicated bronchoscopy for a localized radiographic abnormality. Bronchoalveolar lavage was carried out on the contralateral side in anatomically uninvolved areas.

\section{Effects of bronchoalveolar lavage fluid on lung cell population dynamics}

Three aspects of in vitro cell population dynamics were assessed to provide a comprehensive analysis of the effects of lavage fluid: cell number, DNA synthesis, and death rate. To assess bioactivity of lavage fluid, a human adult lung fibroblast strain (CCD-19Lu; American Type Culture Collection, Rockville, MD) was used between the 8th and 11 th subcultivation. Cells were routinely cultivated $\left(37^{\circ}, 10 \%\right.$ $\mathrm{CO}_{2}$, and $90 \%$ air) in growth medium (DME supplemented with streptomycin $[100 \mu \mathrm{g} / \mathrm{ml}]$, penicillin $[100 \mu \mathrm{g} / \mathrm{ml}]$, and $10 \%$ heat-inactivated bovine calf serum), and subcultivated weekly.

Effects of bronchoalveolar lavage fluid on fibroblast number. To prepare cells for assay, fibroblasts were seeded at $5 \times 10^{3} \mathrm{cells} / \mathrm{cm}^{2}$ (24-well clusters, [Falcon Plastics, Cockeysville, MD]) in growth medium and cultured in that medium for $3 \mathrm{~d}$. Cells were rinsed three times in defined medium (F12 supplemented with bovine serum albumin, 
$0.1 \mathrm{mg} / \mathrm{ml}$; Fe-transferrin, $10 \mu \mathrm{g} / \mathrm{ml}$; selenium, $10^{-8} \mathrm{M}$; and linoleic acid, $3 \times 10^{-6} \mathrm{M}$ ) and were ready for assay. To examine the effect of lavage fluid on cell number, fibroblasts were incubated in varying concentrations of lavage fluid diluted with defined medium. After $3 \mathrm{~d}$, cell number was determined using an electronic particle counter.

Effects of bronchoalveolar lavage fluid on fibroblast DNA synthesis. Fibroblasts were prepared for assay as described above. Cells were incubated $\left(14 \mathrm{~h}, 37^{\circ}\right)$ in the presence of lavage fluid diluted with defined medium $(1: 40 ; \mathrm{vol} / \mathrm{vol})$. Cultures were continued for $4 \mathrm{~h}$ after addition of $3 \mu \mathrm{Ci} / \mathrm{ml}\left[{ }^{3} \mathrm{H}\right]$ thymidine (specific activity $=5.0 \mathrm{Ci} / \mathrm{mmol}$ ). Monolayers were washed three times with $\operatorname{PBS}\left(4^{\circ}\right)$, three times with $5 \%$ trichloroacetic acid $\left(4^{\circ}\right)$, and lysed with $0.5 \mathrm{ml}$ of $0.1 \mathrm{~N} \mathrm{NaOH}$, $0.1 \%$ SDS. Radioactivity was quantified using a liquid scintillation counter. Data were adjusted by normalizing radioactivity to the number of viable cells.

Effects of bronchoalveolar lavage fluid on fibroblast and endothelial cell death rate. Fibroblasts were prepared for assay and incubated with diluted lavage fluid exactly as described for the assessment of DNA synthesis. The conditioned medium was collected and unattached cells were pelleted by centrifugation $(800 \mathrm{~g}$ for $5 \mathrm{~min}$ ). The attached cells were trypsinized, centrifuged, and pooled with unattached cells. This total cell pellet was resuspended in $0.2 \%$ trypan blue and the fraction of dead cells (including the dye) was quantified microscopically in a calibrated counting chamber (11). The data reported represent the average of counting 500 cells in each of triplicate cultures from two separate experiments.

To examine the cytotoxic effect of lavage fluid on another type of lung cell, bovine pulmonary artery endothelial cells (CCL 209; American Type Culture Collection) were used. Cells were maintained in growth medium, subcultivated weekly and used for experiments between the 7th and 11 th subcultivation. Endothelial cell monolayers were cultured with lavage fluid or with TNF- $\alpha(20 \mathrm{ng} / \mathrm{ml})$ for $16 \mathrm{~h}$ as a positive control. The number of dead cells was quantified as for fibroblasts.

\section{Assessment of the mode of cell death induced by lavage fluid}

To define the mode of death, cellular morphology was examined after acridine orange staining (12) as well as by transmission electron microscopy, and the size distribution of DNA molecules $(13,14)$ was determined by electrophoresis. For morphological analysis, fibroblasts were prepared and incubated with lavage fluid as for assessment of DNA synthesis. Endothelial cells were incubated in growth medium for 3 days and cultured $\left(37^{\circ}, 16 \mathrm{~h}\right)$ with lavage fluid, TNF $\alpha(20 \mathrm{ng} / \mathrm{ml})$, and in some experiments with TNF- $\alpha(20 \mathrm{ng} / \mathrm{ml})+$ cycloheximide (3 $\mu \mathrm{g} / \mathrm{ml})$.

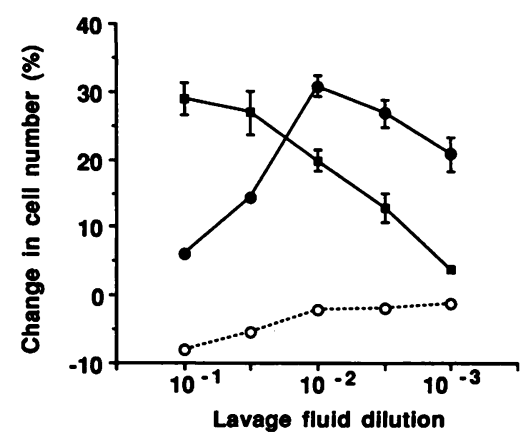

Figure 1. Effect of bronchoalveolar lavage fluid on fibroblast number. Bronchoalveolar lavage fluid obtained from patients during fiberoptic bronchoscopy was examined for its ability to influence lung fibroblast proliferation. To initiate an assay, fibroblasts were seeded and cultured in growth

medium. After $3 \mathrm{~d}$, cells were rinsed in defined medium, incubated three additional days with lavage fluid diluted with defined medium, and counted. Shown is the percent change in cell number observed in response to the indicated dilutions of lavage fluid from each patient group ( $\mathrm{O}$, controls; $\square$, patients early in their clinical course [ $\leq 3 \mathrm{~d}$ after disease onset]; $\bullet$, patients later in their clinical course [ $>10 \mathrm{~d}$ after disease onset ]). Error bars represent one standard deviation and are omitted when they fall within the boundary of the symbol.
Fluorescence microscopy. Cells were washed (PBS, $37^{\circ}$ ), fixed ( $70 \%$ ethanol), and stained with acridine orange $(3 \mathrm{mg} / \mathrm{ml})$. Nuclear morphology was assessed by inverted fluorescence microscopy.

Transmission electron microscopy. Cells were removed from tissue culture dishes in PBS $\left(4^{\circ}\right)$ by gentle scraping, pelleted at low speed in a microcentrifuge tube, and fixed in $0.1 \mathrm{M} \mathrm{Na}$ cacodylate containing $2 \%$ glutaraldehyde, $2 \%$ formalin. Cells were post fixed in $1 \%$ osmium tetroxide followed by uranyl acetate. After dehydration, cell pellets were embedded in Epon. Thin sections were stained with uranyl acetate and lead citrate and examined using an electron microscope (JEOL U.S.A. Inc, Peabody, MA). Detached cells in the media were pelleted and processed as above and examined.

DNA size distribution. For fibroblasts and endothelial cells, analysis of DNA size distribution was performed after a 6-h exposure to bioactive lavage fluid. In addition, for endothelial cells, cultures were incubated $\left(6 \mathrm{~h}, 37^{\circ}\right)$ with TNF- $\alpha(20 \mathrm{ng} / \mathrm{ml})$ as a positive control. Monolayers were washed (PBS, $4^{\circ}$ ) and lysed ( $10 \mathrm{mM}$ Tris, $\mathrm{pH} 7.4$, $100 \mathrm{mM} \mathrm{NaCl}, 1 \mathrm{mM}$ EDTA, $0.5 \%$ Nonidet P40, 0.5\% SDS). DNA was extracted twice with phenol/chloroform (1:1, vol/vol), precipitated by ethanol and incubated $\left(40 \mathrm{~min}, 37^{\circ}\right)$ with ribonuclease $(20$ $\mu \mathrm{g} / \mathrm{ml}$ ). Electrophoresis was carried out in a $1 \%$ agarose gel containing ethidium bromide $(0.5 \mu \mathrm{g} / \mathrm{ml})$.

\section{Effect of cellular proliferative state on the ability of lavage fluid to induce cell death}

To examine the dependence of lavage fluid induction of cell death on proliferative state, $1.5 \times 10^{4}$ fibroblasts or $3 \times 10^{4}$ endothelial cells per well were seeded into 12-well plates in growth medium. Proliferative

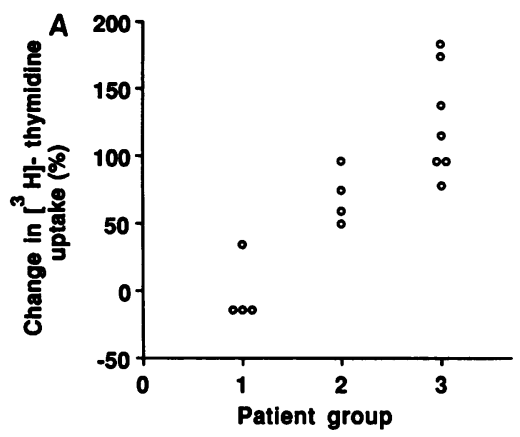

Figure 2. Effects of bronchoalveolar lavage fluid on human lung fibroblast $\left[{ }^{3} \mathrm{H}\right]-$ thymidine incorporation and death rate. Fibroblasts were seeded in growth medium, cultured for $3 \mathrm{~d}$, and rinsed with defined medium. Cells were incubated $\left(14 \mathrm{~h}, 37^{\circ}\right)$ in the presence of lavage fluid from each patient group diluted with defined medium ( $1: 40 ; \mathrm{vol} / \mathrm{vol})$ (group 1, control; group 2 , patients studied $\leq 3 \mathrm{~d}$ after disease onset; group 3, patients studied $>10 \mathrm{~d}$ after disease onset). ( $A$ ) Cultures were continued for $4 \mathrm{~h}$ after addition of $\left[{ }^{3} \mathrm{H}\right]-$ thymidine. Shown is the percent change in $\left[{ }^{3} \mathrm{H}\right]-$ thymidine incorporation by fibroblasts in response to lavage fluid compared to the response to defined medium alone $(978 \pm 142 \mathrm{cpm})$ for each patient group. Thymidine incorporation in the positive control (defined medium supplemented with $\mathrm{PDGF}=100 \mathrm{pM}, \mathrm{EGF}=100 \mathrm{pM}$, and insulin $=100 \mathrm{nM}$ ) was $3,485 \pm 274 \mathrm{cpm}$. $(B)$ Fibroblast death rate was quantified using $0.2 \%$ trypan blue. Dead cells were counted microscopically in a calibrated counting chamber. The data represent the average of counting 500 cells in each of triplicate cultures from two separate experiments. 


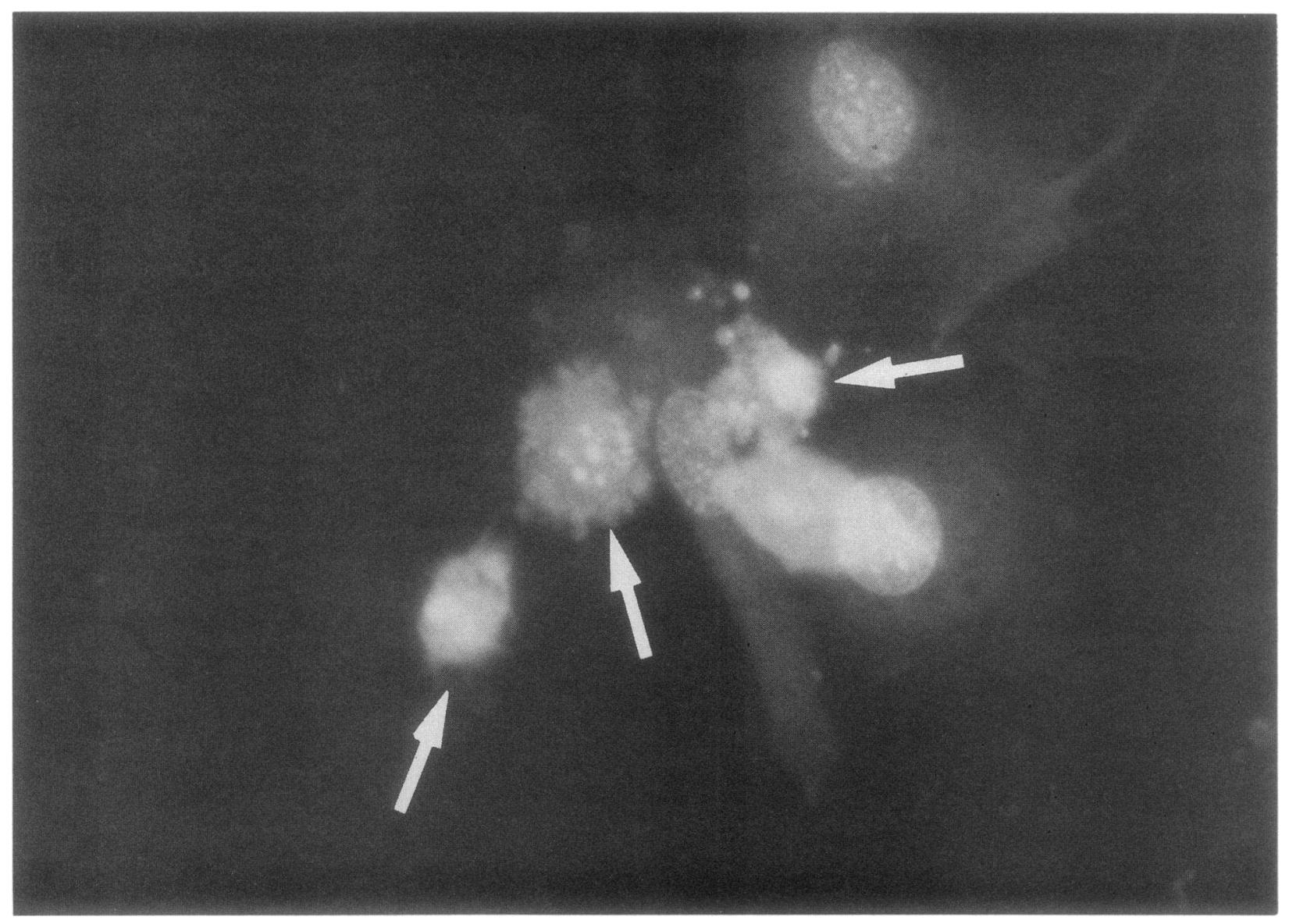

Figure 3. Effects of bioactive lavage fluid on endothelial cell morphology: phase contrast microscopy. Cells were incubated with lavage fluid diluted with defined medium (1:40, vol/vol) from patients during lung repair ( $>10 \mathrm{~d}$ after disease onset). After a 16-h incubation, cells were washed, fixed, stained with acridine orange, and examined by inverted phase contrast fluorescence microscopy. Shown is an example of endothelial cells incubated with bioactive lavage fluid demonstrating the nuclear morphology typical of apoptosis (arrows).

state was modulated as follows: exponentially growing cells were produced by incubation in growth medium for $48 \mathrm{~h}$; noncycling cells were produced by rinsing proliferating cells three times with defined medium and continuing cultures in that medium for $48 \mathrm{~h}$; growth-stimulated cells were produced by culturing noncycling cells in growth medium for $24 \mathrm{~h}$. To assess the ability of lavage fluid to induce cell death, cells were washed twice with defined medium and incubated in that medium with (1:40, vol/vol) or without (control) lavage fluid for $24 \mathrm{~h}$. Cell death was quantified as the percentage of cells stained with trypan blue.

\section{Biophysical and biochemical properties of the bioactivity}

To define some of the biophysical and biochemical properties of the observed bioactivity, heat stability, proteinase sensitivity, and lipid solubility was examined. Bioactivity of lavage fluid obtained $10 \mathrm{~d}$ after lung injury was tested for heat stability by incubation at $56^{\circ}(45 \mathrm{~min})$ or $100^{\circ}(15 \mathrm{~min})$. Trypsin sensitivity was tested by incubating $0.1 \mathrm{ml}$ of lavage fluid containing $25 \mu \mathrm{g}$ of protein with $2.5 \mathrm{mg}$ of trypsin (Sigma Immunochemicals, St. Louis, MO) at $37^{\circ}$ for $1 \mathrm{~h}$. The trypsin was inactivated with $0.57 \mathrm{mg}$ of soybean trypsin inhibitor (Sigma Immunochemicals). After each treatment, bioactivity was assayed using trypan blue exclusion. To assess lipid solubility, lavage fluid diluted with medium F12 (1:40; final volume $=5 \mathrm{ml})$ was mixed with an equal volume of ethyl acetate. After $5 \mathrm{~min}$ of shaking, the organic and aqueous phases were separated and lyophilized. The aqueous lyophilized material was dissolved in $5 \mathrm{ml}$ of water. The organic phase was dissolved in $20 \mu \mathrm{l}$ of $70 \%$ ethanol and brought up to $5 \mathrm{ml}$ with medium F12. Cells were incubated in the presence of extracted (undiluted) and untreated lavage fluid (1:40) for $24 \mathrm{~h}$ and stained with trypan blue. To assess the similarity of the bioactivity to the known inducer of endothelial cell apoptosis, TNF- $\alpha$, anti-TNF- $\alpha$ antibody $(1 \mu \mathrm{g} / \mathrm{ml})$ was incubated with lavage fluid $\left(2 \mathrm{~h}, 37^{\circ}\right)$ before assay. The concentration of antibody used was sufficient to neutralize $20 \mathrm{ng} / \mathrm{ml}$ of TNF- $\alpha$. This represents a 10 -fold excess above the highest concentration reported to occur in patients with acute lung injury (15). The ability of the antibody to neutralize TNF- $\alpha$ was validated in the concentration range used with the endothelial cell apoptosis assay (acridine orange staining).

\section{Morphological analysis of lung tissue}

Open lung biopsies were performed on two patients with acute lung injury as part of their routine clinical evaluation, 10 or $13 \mathrm{~d}$ after disease onset. Both eventually recovered completely. Tissue was fixed in $10 \%$ buffered formalin, routinely processed, and stained with hematoxylin and eosin. Each bud of intraalveolar granulation tissue was examined for morphological evidence of mesenchymal cell death.

\section{Results}

Effects of lavage fluid on cell population dynamics. When human lung fibroblasts were cultivated in defined medium supplemented with bronchoalveolar lavage fluid obtained from patients with acute lung injury, a net increase in cell number was observed (Fig. 1). This result was obtained whether the fluid was recovered from patients during the early inflammatory phase of the illness ( $\leq 3 \mathrm{~d}$ after disease onset), or later on during alveolar repair after acute inflammation had subsided ( $>10 \mathrm{~d}$ after disease onset). Lavage fluid from patient controls 

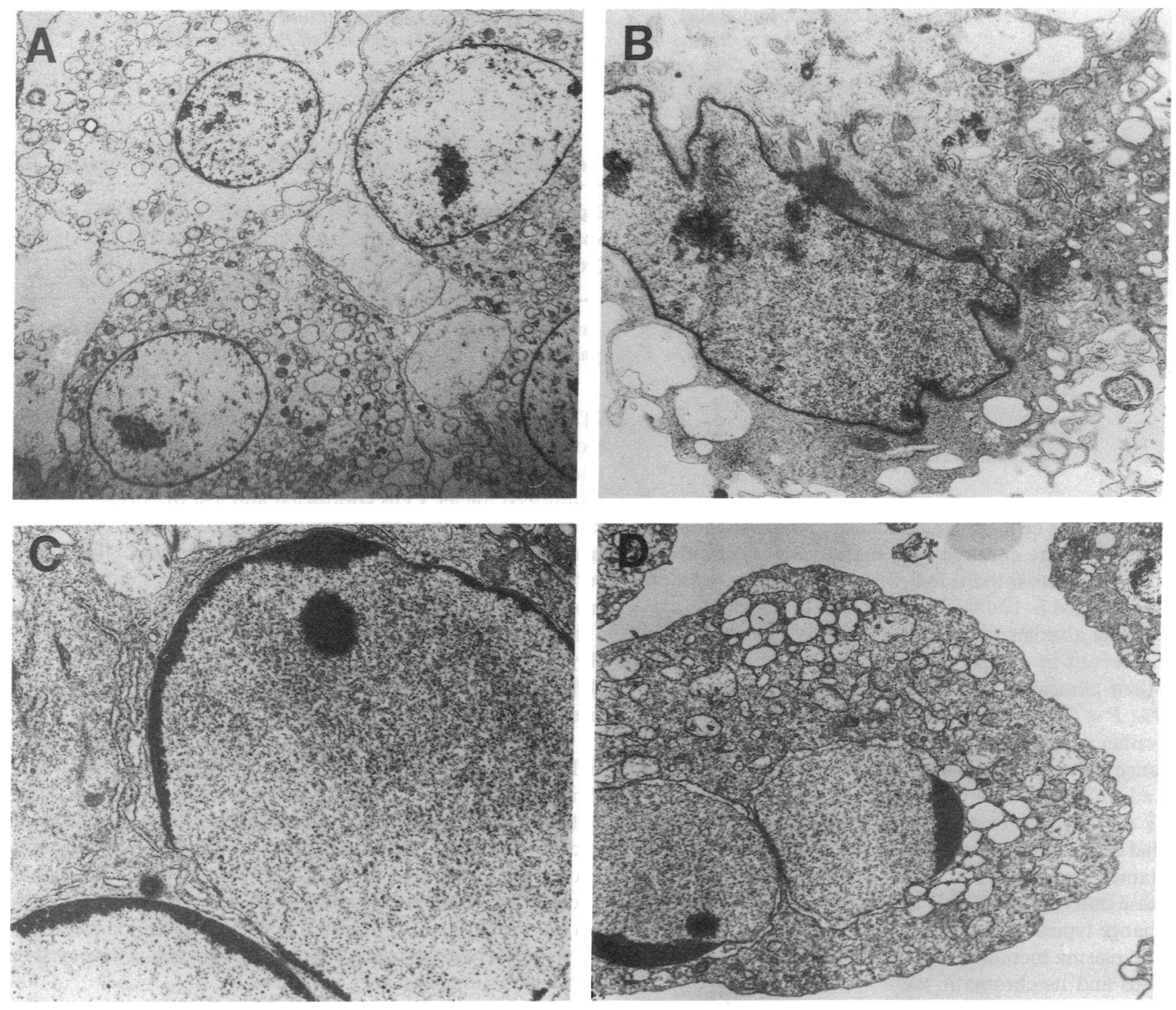

Figure 4. Ultrastructural analysis of endothelial cells. Endothelial cells were cultured with medium or bioactive lavage fluid for $16 \mathrm{~h}$; or with the combination of TNF- $\alpha(20 \mathrm{ng} / \mathrm{ml})$ and cycloheximide for $3 \mathrm{~h}$. Cells were fixed and processed for transmission electron microscopy as described in methods. $A$ Demonstrates normal endothelial cells, prepared in parallel with the samples shown in $B-D$ and the fibroblasts in Fig. 7. The cells have single, round nuclei with some central chromatin clumping, and many cytoplasmic vesicles (magnification $=2.2 \times 10^{3}$ ). $B$ Is a micrograph of an endothelial cell cultured with bioactive lavage fluid (magnification $=5.8 \times 10^{3}$ ). The nucleus is invaginated and no longer smooth or round. $C$ Is a higher power micrograph of a detached endothelial cell cultured with bioactive lavage fluid $\left(\right.$ magnification $\left.=8.1 \times 10^{3}\right)$. The cell is binucleate and has peripheral chromatin condensation around the nuclear membrane. $D$ Is a low power micrograph of endothelial cells cultured with TNF- $\alpha$ and cycloheximide as a positive control. A binucleate or lobulated nucleus is evident that was not found in control endothelial cells (magnification $=4.3 \times 10^{3}$ ).

did not influence lung fibroblast numbers. Experiments in which bioactive lavage fluid was mixed with lavage fluid from patient controls indicated this result was not accounted for by growth inhibitors (not shown). Decreasing concentrations of lavage fluid from patients early in the disease process led to a monotonic decline in fibroblast growth. In contrast, the fibroblast growth response to decreasing concentrations of lavage fluid from patients during alveolar repair was biphasic. Cell numbers increased to a maximum value as the fluid was diluted, followed by a monotonic decline in growth stimulatory bioactivity to baseline values. This pattern suggested the lavage fluid from this latter group of patients contained a mixture of stimulatory and inhibitory bioactivities.

To confirm the results obtained with direct cell counts, in- corporation of $\left[{ }^{3} \mathrm{H}\right]$ thymidine into lung fibroblast DNA following lavage fluid treatment was assessed. Unexpectedly, the highest rate of DNA synthesis occurred in response to fluid obtained from patients during alveolar repair, and not in response to fluid obtained early in the clinical course, as the direct cell counts would have predicted (Fig. $2 A$ ). One possibility that could explain this observation, was that cell death occurred at a rate that balanced the rate of cell replication. In accord with this possibility, incubation of lung fibroblasts with lavage fluid from patients during alveolar repair induced a three- to fourfold increase in the number of dead cells observed (Fig. $2 \mathrm{~B}$ ). In contrast, fluid from patients early in their clinical course or from patient controls did not significantly alter the rate of fibroblast death. 


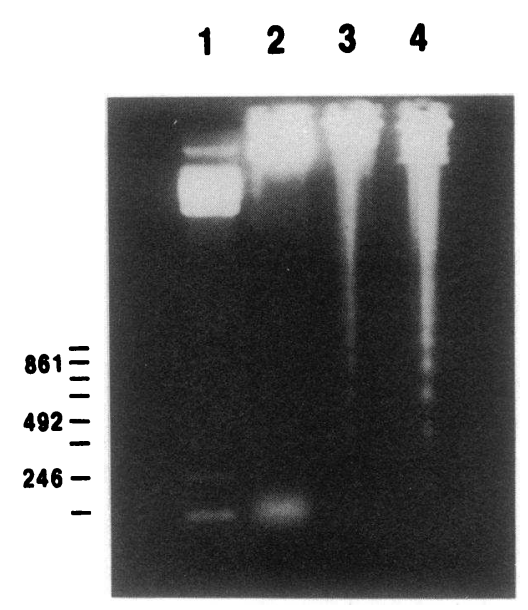

Figure 5. Endothelial cell DNA size distribution analysis. Cells were incubated with medium, lavage fluid from patients during lung repair (diluted 1:40) or TNF- $\alpha$. After a 6-h incubation, DNA was extracted and electrophoresed in a $1 \%$ agarose gel. (Lane 1) DNA size markers. (Lanes 2-4) DNA from endothelial cells cultured in medium (lane 2), bioactive lavage fluid (lane 3 ), or TNF- $\alpha ; 20 \mathrm{ng} / \mathrm{ml}$ (lane 4).

The other major cellular constituent of granulation tissue, endothelial cells, were cultured with bioactive lavage fluid ( $n$ $=4$ ) in a manner similar to the lung fibroblasts. The number of dead cells increased 8-10-fold in response to lavage fluid from patients during alveolar repair $(9.4 \pm 1.6 \%)$, compared to the number observed in response to lavage fluid from patients early in their clinical course $(1.2 \pm 0.7 \%)$ or patient controls $(1.4 \pm 0.9 \% ; P<0.01$ for samples during alveolar repair compared to either early samples or controls). There was complete concordance between the ability of a given sample of lavage fluid to induce the death of fibroblasts and endothelial cells.

Mode of cell death in response to lavage fluid. Culturing endothelial cells in defined medium supplemented with lavage fluid obtained from patients during alveolar repair $(>10 \mathrm{~d}$ after disease onset) reproducibly led to a sequence of morphological change typical of apoptosis (Fig. 3). Within 2-3 h, ruffling of the plasma membrane was observed. Condensation of the nucleus and its chromatin were apparent after 6-8 h of culture with lavage fluid, followed by formation of dense nuclear bodies. By ultrastructural analysis, endothelial cells exposed to lavage fluid demonstrated lobulation and fragmentation of the nucleus that was not seen in control cells (Fig. 4, $A$ and $B$ ). When endothelial cells were exposed to TNF- $\alpha$, some of the cells detached from the tissue culture dishes. The nuclei of these detached cells were fragmented and had marked chromatin condensation (Fig. $4 C$ ). These changes were accentuated by combining TNF- $\alpha$ with cycloheximide (Fig. $4 D$ ). Consistent with the recent data of Robaye and co-workers (16), agarose gel electrophoresis of nuclear DNA from endothelial cells treated with TNF- $\alpha(20 \mathrm{ng} / \mathrm{ml})$ for $16 \mathrm{~h}$ demonstrated the internucleosomal cleavage pattern characteristic of apoptosis (Fig. 5). Samples of DNA from endothelial cells incubated in the presence of lavage fluid from patients during lung repair revealed a similar DNA size distribution. When endothelial cells were cultured in parallel with medium, or lavage fluid from patients early in their clinical course $(<3 \mathrm{~d}$ after disease onset), morphology did not change, and internucleosomal DNA cleavage was not observed.

When human lung fibroblasts were cultured in bioactive lavage fluid, cells underwent morphological changes distinct from apoptosis. The patterns observed closely resembled those described previously by Scher et al. (17) and Tamm et al. (18, 19 ) in serum-deprived cultures of density-inhibited BALB/c
Table I. Dependence of Lavage Fluid Induction of Physiological Cell Death on Cell Proliferative State

\begin{tabular}{lccccc}
\hline & \multicolumn{4}{c}{ Cell death (\%) } \\
\cline { 2 - 3 } \multicolumn{1}{c}{ Proliferative state } & Control & Lavage fluid & & Control & Lavage fluid \\
\cline { 2 - 3 } \cline { 5 - 6 } & & \multicolumn{2}{c}{ Fibroblasts } & & Endothelial cells \\
\hline Exponential growth & $10.3 \pm 0.40$ & $21.0 \pm 0.14^{*}$ & & $1.8 \pm 0.20$ & $8.1 \pm 0.38^{*}$ \\
Noncycling & $8.4 \pm 0.63$ & $7.4 \pm 0.68$ & & $4.8 \pm 0.92$ & $3.2 \pm 0.72$ \\
Growth stimulated & $9.3 \pm 0.12$ & $20.0 \pm 0.90^{*}$ & & $3.2 \pm 0.73$ & $7.9 \pm 1.14^{*}$
\end{tabular}

Data are expressed as the mean \pm SD. ${ }^{*} P<0.01$ compared to control (paired $t$ test).

3T3 murine fibroblasts. Cell death was first observed after 5-6 $\mathrm{h}$ of incubation with lavage fluid. As revealed by fluorescence microscopy, dying fibroblasts contained crescent-shaped or multilobed nuclei. Cells contracted and lost their typical spindle-like shape until only tightly condensed nuclear bodies remained in deformed, contracted cytoplasm (Fig. 6). Ultrastructural analysis of fibroblasts exposed to lavage fluid revealed nuclear lobulations that were not seen in normal fibroblasts (Fig. 7). Agarose gel electrophoresis of nuclear DNA reproducibly revealed a cleavage pattern distinct from control, but also different from the internucleosomal cleavage pattern typically observed during apoptosis (Fig. 8).

The proliferative state of both lung fibroblasts and endothelial cells in vitro significantly influenced the proportion of cells dying in response to a given concentration of lavage fluid. While noncycling cells were nearly insensitive to the effects of bioactive lavage fluid, dividing cells manifested up to a twofold increase in death rate for fibroblasts, and a three to fourfold increase in death rate for endothelial cells (Table I). This observation supports a potential role for the observed bioactivity in vivo, where trophic factors and mesenchymal cells coexist in the alveolar airspace.

Biophysical and biochemical properties of the bioactivities in lavage fluid. The cell death promoting bioactivities for both fibroblasts and endothelial cells were trypsin sensitive (Table II). After ethyl acetate extraction, the bioactivity for both cell types remained in the aqueous phase. However, thermal stability at $100^{\circ}$ distinguished the bioactivity for the two cell types. The bioactivity for fibroblasts was heat stabile, while the bioactivity for endothelial cells was heat labile. Preincubation of bioactive lavage fluid with neutralizing anti-TNF- $\alpha$ antibodies

Table II. Biophysical and Biochemical Properties of the Bioactivity

\begin{tabular}{ccc}
\hline & \multicolumn{2}{c}{ Percent activity remaining } \\
\cline { 2 - 3 } Treatment & Fibroblasts & Endothelial cells \\
\hline Heating & & \\
$56^{\circ}$ & $119 \pm 8$ & $89 \pm 8$ \\
$100^{\circ}$ & $96 \pm 10$ & $3 \pm 0.4$ \\
Trypsin & 0 & $8 \pm 1.4$ \\
Ethyl acetate & $121 \pm 8$ & $113 \pm 7$ \\
Aqueous phase & 0 & 0 \\
Organic phase & $94 \pm 7$ & $98 \pm 6$ \\
Anti-TNF- $\alpha$ antibodies & & \\
\hline
\end{tabular}



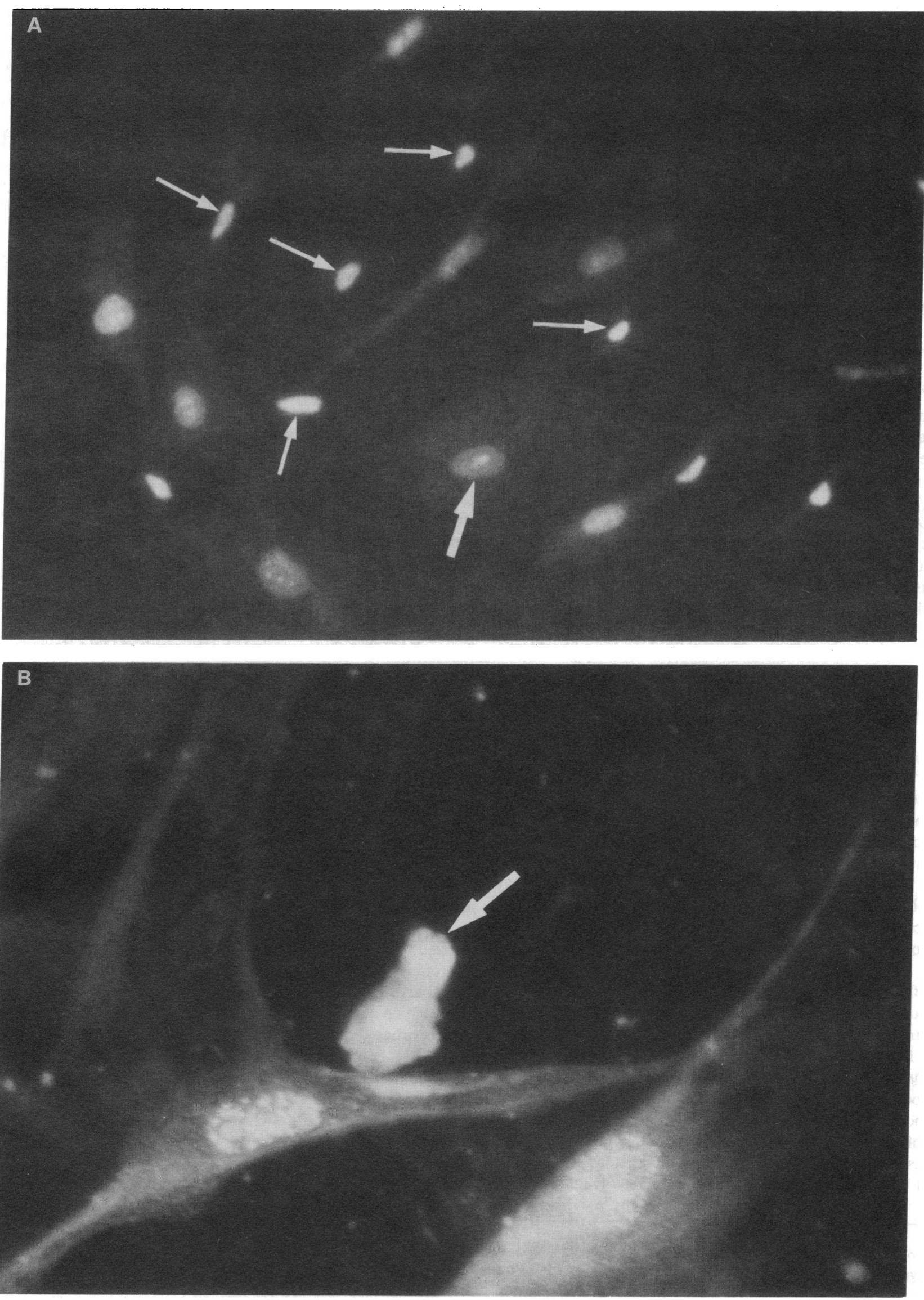
did not alter the observed induction of either fibroblast or endothelial cell death. Taken together, this data indicated that peptides capable of inducing lung fibroblast and endothelial cell death in vitro distinct from TNF- $\alpha$, were present on the alveolar epithelial surface during alveolar repair.

Morphological analysis of lung tissue. To assess a possible role for the induction of mesenchymal cell death in lung remodeling in vivo, we sought morphological evidence of this process within intraalveolar granulation tissue. Examination of histological sections from lung biopsies of patients $(n=2)$ who eventually recovered from lung injury showed several cells with a nuclear morphology similar to that observed after culture with bioactive lavage fluid in vitro. These cells were found mainly within areas of young fibroblastic proliferation projecting into alveolar spaces (Fig. 9), restricted largely to regions where the granulation tissue was covered by epithelial cells, suggesting that this tissue was in the process of regression rather than formation.

\section{Discussion}

The control of cell populations in tissues of multicellular organisms is achieved by a coordinated interaction of positive and negative growth regulators. Positive signals stimulate progression of cells toward mitosis, whereas negative signals either prevent this progression or induce cell death. A major biological process tightly connected with such population control is the repair of injured tissues. Our studies have been directed at examining the alveolar microenvironment in patients after acute lung injury to identify growth regulatory signals responsible for the exuberant intraalveolar granulation tissue characteristically observed as lung repair ensues $(9,10)$. During experiments examining the effects of lavage fluid on lung fibroblast proliferation, negative as well as positive growth regulatory signals were observed. Since repair of the gas exchange apparatus after acute lung injury requires prompt and orderly elimination of fibroblasts and endothelial cells from the alveolar airspace, we examined the possibility that signals capable of inducing the death of these cells were present at the air-lung interface. In accord with this possibility, samples obtained from the alveolar surface of patients during lung repair contained peptide(s) that induced both fibroblast and endothelial cell death, while those obtained at the time of injury or from normal individuals did not. Histological examination of lung tissue obtained from patients as the lung was repairing revealed evidence of mesenchymal cell death within the airspace. The mode of endothelial cell death was apoptosis as defined by typical morphology and intranucleosomal DNA cleavage. While the mode of fibroblast death could not be definitively resolved, a process similar to that described by Scher et al. (17) and Tamm et al. $(18,19)$ in response to growth factor withdrawal from BALB $/ 3 T 3$ cells was observed.

Mode of cell death in eukaryotic cells. There are generally felt to be two major modes of death in eukaryotic cells, necrosis and apoptosis. Pathologic cell death or necrosis occurs as a result of insufficient substrate (e.g., hypoxia, hypoglycemia) or noxious stimuli (20). Necrosis is characterized by cell swelling caused by loss of plasma membrane integrity. It represents a complete breakdown of tissue organization after a quantum departure from physiological conditions. Morphological features of necrosis include uncontrolled swelling of nuclear and cytoplasmic components with conservation of nucleoli. Heterochromatin orientation remains unaltered against a background of gross cytoplasmic degradation (21). The products of necrosis elicit an acute exudative inflammatory response in adjacent viable tissues. This process characterizes the earliest phases of acute lung injury where epithelial and endothelial necrosis, as well as an explosive acute inflammatory response, are typically observed.

When cell death occurs in the context of an organized tissue response, as in development, endocrine-dependent tissue atrophy, or normal tissue turnover, an orderly process termed programmed cell death or apoptosis occurs $(21,22)$. Morphologically, there is cell shrinkage, condensation and segmentation of the nucleus. Chromatin fragmentation and membrane blebbing also are observed. Biochemically there is activation of nucleases that hydrolyze DNA with a typical internucleosomal cleavage pattern.

The present investigation provides evidence that more than one biological process may be involved in mesenchymal cell population control during lung remodeling after injury. When cultured with lavage fluid obtained from patients during alveolar repair, endothelial cells undergo apoptosis while lung fibroblasts display progressive nuclear segmentation and cellular contraction, without clear evidence of progressive chromatin condensation or fragmentation. In the course of dying, fibroblasts form mulberry-like structures with ruffled borders and contracted nuclei. DNA cleavage into nucleosome-sized fragments is not observed. Instead, we observe an electrophoretic "smear" of DNA that appears to be the result of DNA degradation in random-sized fragments after chromatin disintegration. Of note, the mode of fibroblast death observed in our study did not conform completely to the patterns typical of either apoptosis or necrosis.

While still an open question, the mode of fibroblast death observed may be a form of physiological or programmed cell death closely akin to that described by Scher et al. (17) and Tamm et al. $(18,19)$. They also observed cell contraction, cytoplasmic blebbing, and nuclear segmentation in BALB/c 3T3 fibroblasts deprived of serum. Similar to our results, neither chromatin fragmentation nor nucleosomal-size DNA cleavage was observed.

Regulation of programmed cell death. Previously characterized signals that induce programmed cell death are generally steroid or peptide in nature. For example, steroid hormones capable of inducing programmed cell death include progesterone, which acts on estrogen exposed endometrium (23), and glucocorticoids, which target specific populations of lymphoid cells (13). Peptides capable of inducing programmed cell death include the Mullerian inhibiting substance that leads to elimination of the Mullerian ducts in males (24), and the cytokines TGF- $\beta(25)$ and TNF- $\alpha$, which induce both programmed cell death and necrosis in variety of mammalian cells $(26,27)$. Consistent with this information, at least two distinct bioactivities, one heat labile and one heat stable, were identified at the

Figure 6. Effects of bioactive lavage fluid on fibroblast morphology: phase contrast microscopy. Fibroblast monolayers were cultured in medium or lavage fluid diluted with defined medium $(1: 40)$ from patients during alveolar repair ( $>10 \mathrm{~d}$ after disease onset). Cells were washed, fixed, and stained with acridine orange. Nuclear morphology was assessed by inverted phase fluorescence microscopy. $(A)$ Shown are representative examples of normal fibroblasts (thick arrow) and cells with condensed nuclei (thin arrows) after a 6-h exposure to bioactive lavage fluid ( $\times 600$ ). $(B)$ Higher power view of cell morphology after a 16-h exposure to bioactive lavage fluid is shown $(\times 900)$. 

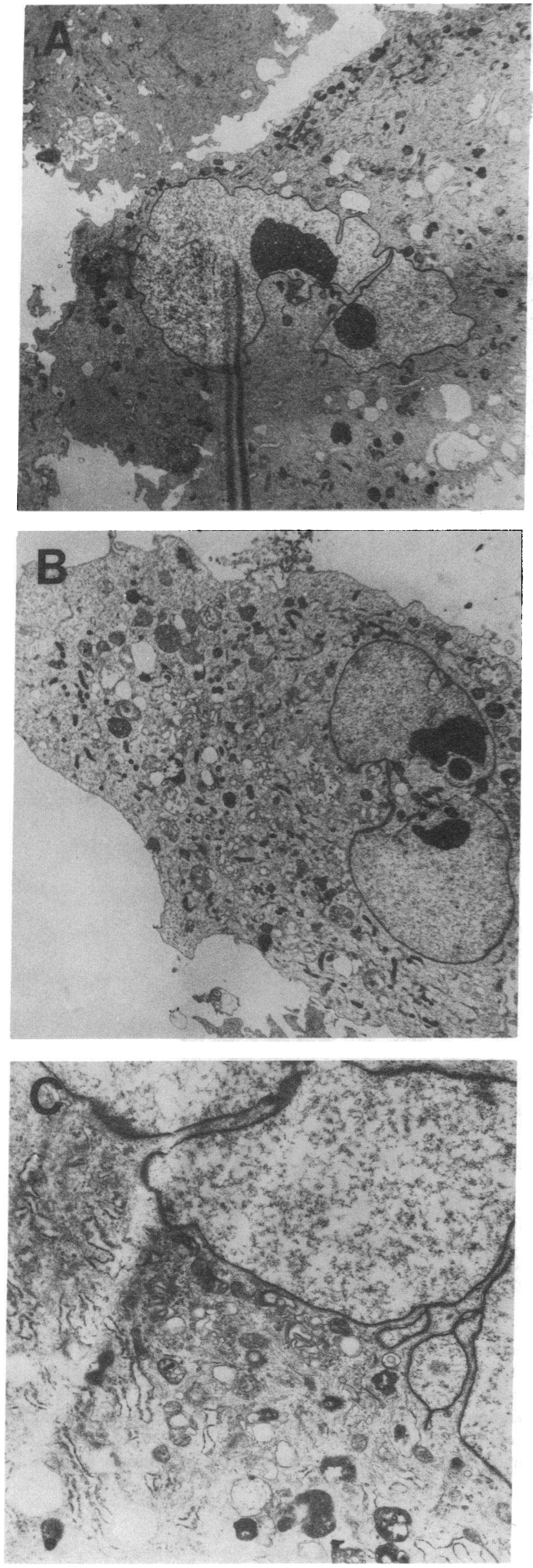

\section{4}

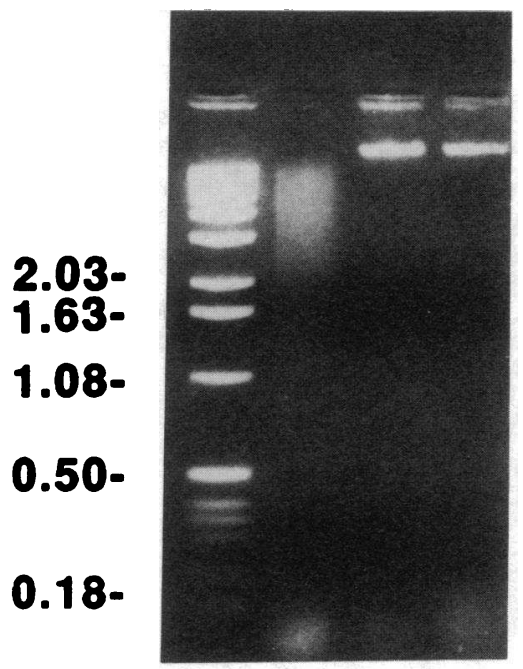

Figure 8. Fibroblast DNA size distribution analysis. Fibroblasts were cultured for $6 \mathrm{~h}$ with lavage fluid (1:40) or medium, DNA extracted and subjected to electrophoresis in $1 \%$ agarose gels. (Lane 1) DNA size markers. (Lanes 2-4) DNA from fibroblasts treated with lavage fluid obtained during alveolar repair (lane 2) or early lung injury (lane 3 ), or from untreated cells (lane 4).

air-lung interface of patients during lung repair in the present study. Both have the biophysical/biochemical properties of peptides, and both induce cell death principally in proliferating target cells. These peptides appear to be distinct from TNF- $\alpha$, since their bioactivity was not influenced by neutralizing antiTNF- $\alpha$ antibodies.

Two general paradigms are involved in the induction of programmed cell death. In some situations, it can be induced by withdrawal of trophic signals. Examples include prostatic involution after withdrawal of testosterone (28), or hematopoetic precursor cell death after removal of the corresponding colony stimulating factor (29) or interleukins $(30,31)$. In other situations programmed death is induced by introduction of a signal into the microenvironment. This occurs during ontogeny when the Mullerian ducts regress in males in response to Mullerian inhibiting substance (24). During lung repair, this latter paradigm appears to be followed, since lavage fluid inducing cell death also contains sufficient trophic activity to stimulate lung mesenchymal cell proliferation. This strongly suggests that trophic factor deficiency is not occurring in vivo. It also contrasts with the results in BALB/c 3T3 cells where withdrawal of peptide growth factors induces cell death, a process that can be abrogated by the timely addition of growth factors (17-19).

Molecular mechanisms of programmed cell death. At present, the interrelationships between ligand-receptor interaction, cell cycle events, and intracellular effector mechanisms in programmed cell death are incompletely understood. Possible signaling mechanisms in the initiation of this process include such cell cycle-related processes as calcium influx (32), protein kinase $C$ activation (33) altered expression of protooncogenes such as c-myc $(34-36)$, bcl-2 $(37,38)$, and the tumor suppres-

Figure 7. Effects of bioactive lavage fluid on fibroblast morphology: transmission electron microscopy. Fibroblasts cultured as described in the legend to Fig. 6 were processed for transmission electron microscopy. Lavage fluid induced nuclear lobulation and some degree of chromatin condensation, demonstrated in two cells $(A$ and $B)$. At higher magnification, the lobulation of the nuclear membrane into pinched off smaller portions was seen $(C)$. Magnification $=1.5$ $\times 10^{3}, 1.8 \times 10^{3}$, and $4.7 \times 10^{3}$, respectively. 

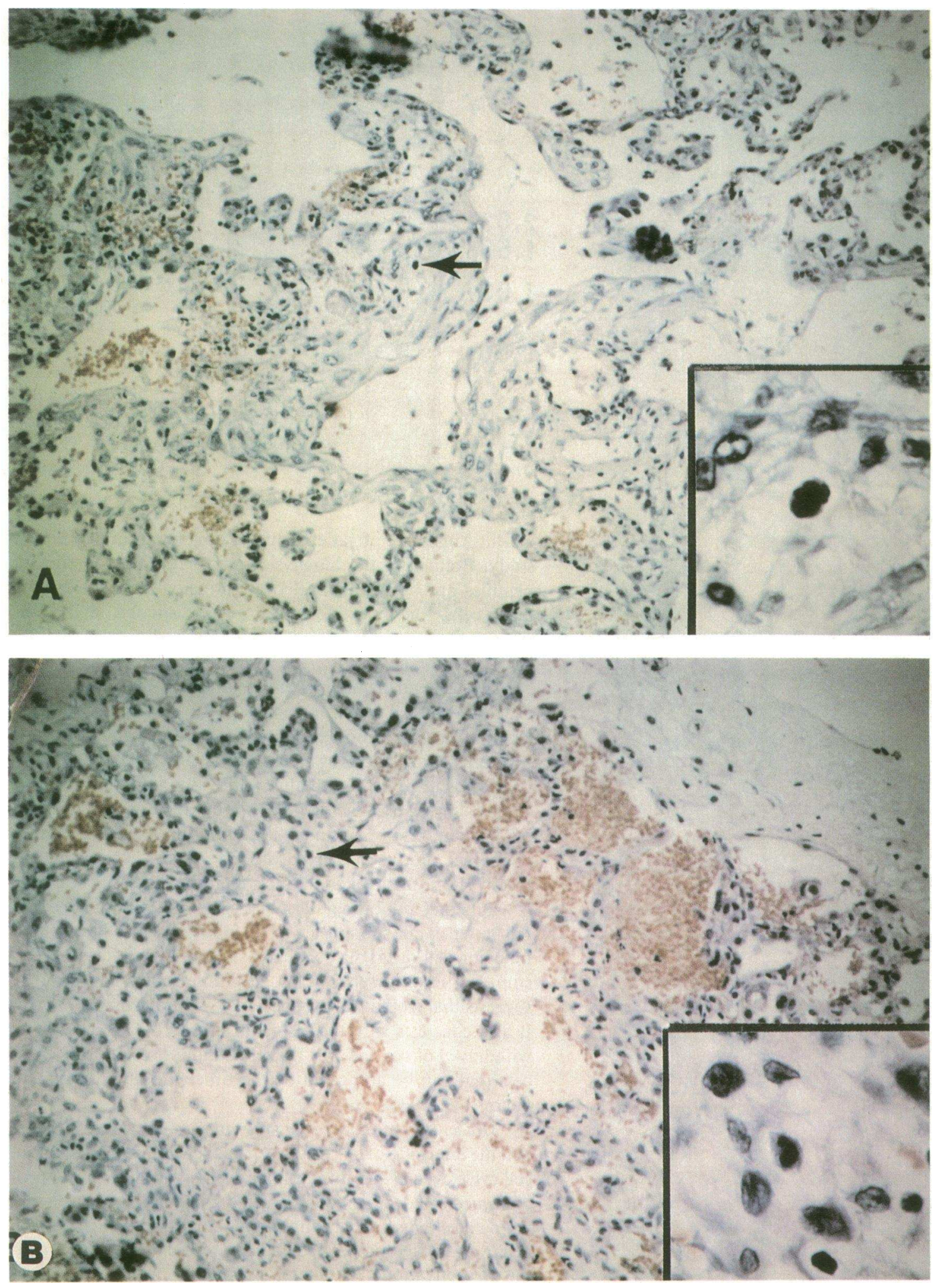

Figure 9. Histologic assessment of lung biopsies obtained from patients with acute lung injury. Open lung biopsies were performed on two patients with acute lung injury as part of their routine clinical evaluation, 10 or $13 \mathrm{~d}$ after disease onset. Both eventually recovered completely. Tissue was fixed in $10 \%$ buffered formalin and routinely processed and stained with hematoxylin and eosin $(\times 100$; inset, $\times 600)$. Resolving acute lung injury showing interstitial thickening, buds of immature fibroblast proliferation and hemorrhage. These two biopsies show, in addition, occasional cells (arrows) morphologically similar to those undergoing programmed death in vitro after culture with bioactive lavage fluid (detailed in the insets). Note that in $(A)$, the cell appearing to undergo programmed death is present in an area where the fibroblastic plug has clearly reepithelialized. 
sor gene p53 (30). Examination of these issues in repairing lung will require identification and purification of the observed bioactivity.

Clinical implications. A more thorough understanding of the normal homeostatic mechanisms engaged by the body to control a fibroproliferative response may provide clinicians with novel therapeutic directions for a number of disorders for which little in the way of therapy is currently available. The broad class of fibroproliferative disorders include atherosclerosis, as well as acute and chronic fibrosis of the lung, liver, and kidney. Currently no effective means of controlling a fibroproliferative response is available. In this connection, our data indicates that lung injury and repair represents a useful experimental system for understanding the general biological process of repair and remodeling after tissue injury. Its utility derives from the precisely defined kinetics of the cellular events and our ability to safely, repetitively, and with minimal pertubation obtain biological samples directly from the region of interest. Potential applications of our findings will of necessity await purification and characterization of the bioactivity, as well as the examination of the role of programmed cell death in the body's response to other pathological and physiological fibroproliferative processes.

\section{Acknowledgments}

The authors would like to thank Dr. James O'Leary for insightful suggestions, Dr. James Jamieson for assistance in interpreting the ultrastructural data, Pat Jung for her expert technical assistance with electron microscopy, Dr. James McCarthy for his review of the manuscript, Elaina Davis for assistance in preparing the manuscript, and especially Max, for assistance with biochemical characterization.

This work was supported in part by National Institutes of Health (NIH) grant 5RO1 HL-39833 (Dr. Bitterman); University of Minnesota Grant-in-Aid 14966 (Dr. Ingbar); NIH NRSA grant F32 HL08051-02 (Dr. Henke); ALA Research Fellowship Award (Dr. Wendt); and NIH NCRR MO1 grant RR-004400 to the Clinical Research Center, University of Minnesota.

\section{References}

1. Pontoppidan, H., P. C. Huttemeier, and D. A. Quinn. 1985. Etiology, demography, and outcome in acute respiratory failure. In Acute Respiratory Failure. W. M. Zapol and K. J. Falke, editors. Marcel Dekker, Inc., New York. pp. 1-21.

2. Fowler, A. A., R. F. Hamman, G. O. Zerbe, K. N. Benson, and T. M. Hyers. 1985. Adult respiratory distress syndrome: prognosis after onset. Am. Rev. Respir. Dis. 132:472-478.

3. Schraufstatter, I. U., S. D. Revak, and C. G. Cochrane. 1984. Proteases and oxidants in experimental pulmonary inflammatory injury. J. Clin. Invest. 73:1175-1184.

4. Fantone, J. C., and P. A. Ward. 1982. Role of oxygen-derived free radicals and metabolites in leukocyte dependent inflammatory reactions. Am. J. Pathol. 107:397-418.

5. Fukuda, Y., M. Ishizake, Y. Masuda, G. Kimura, O. Kawanami, and Y. Masugi. 1987. The role of intraalveolar fibrosis in the process of pulmonary structural remodeling in patients with diffuse alveolar damage. Am. J. Pathol. 126:171-182.

6. Katzenstein, A. A., J. L. Myers, and M. U. Mazur. 1986. Acute interstitial pneumonia: a clinicopathologic, ultrastructural and cell kinetic study. Am. J. Surg. Pathol. 10:256-267.

7. Kapanci, Y., E. R. Weibel, H. P. Kaplan, and F. R. Robinson. 1969. Pathogenesis and reversibility of the pulmonary lesions of oxygen toxicity in monkeys. Lab. Invest. 20:101-118.

8. Rotman, H. H., T. F. Lavelle, Jr., D. G. Dimcheff, R. J. VandenBelt, and J. G. Weg. 1977. Long-term physiologic consequences of the adult respiratory distress syndrome. Chest. 72:190-192.

9. Snyder, L. S., M. I. Hertz, M. S. Peterson, K. R. Harmon, W. A. Marinelli, C. A. Henke, J. R. Greenheck, B. Chen, and P. Bitterman. 1991. Acute lung injury. Pathogenesis of intraalveolar fibrosis. J. Clin. Invest. 88:663-673.

10. Henke, C. A., V. Fiegel, M. Peterson, M. Wick, D. Knighton, J.
McCarthy, and P. B. Bitterman. 1991. Identification and partial characterization of angiogenesis bioactivity in the lower respiratory tract after acute lung injury. $J$. Clin. Invest. 88:1386-1395.

11. Patterson, M. K. 1979. Measurement of growth and viability of cells in culture. Methods Enzymol. 58:141-152.

12. Gregory, C. D., C. Dive, S. Anderson, C. A. Smith, G. T. Williams, J. Gordon, and A. B. Rickinson. 1991. Activation of Epstein-Barr virus latent genes protects human B cells from cells by apoptosis. Nature (Lond). 349:612-614.

13. Wyllie, A. H. 1980. Glucocorticoid-induced thymocyte apoptosis is associated with endogenous endonuclease activation. Nature (Lond.). 284:555-556.

14. Arends, M. J., R. G. Morris, and A. H. Wyllie. 1990. Apoptosis: the role of the endonuclease. Am. J. Pathol. 136:593-608.

15. Hyers, T. M., S. M. Tricomi, P. A. Dettenmeier, and A. A. Fowler. 1991. Tumor necrosis factor levels in serum and bronchoalveolar lavage fluid of patient with the adult respiratory distress syndrome. Am. Rev. Respir. Dis. 144:268-271.

16. Robaye, B., R. Mosselmans, W. Fiers, J. Dumont, and P. Galand. 1991. Tumor necrosis factor induces apoptosis (programmed cell death) in normal endothelial cells in vitro. Am. J. Pathol. 138:447-485.

17. Scher, C. D., S. A. Young, and K. L. Locatell. 1982. Control of cytolysis of BALB/c 3T3 cells by platelet-derived growth factor: a model system for analyzing cell death. J. Cell. Physiol. 113:211-218.

18. Tamm, I., and T. Kikuchi. 1990. Insulin-like growth factor-1 (IGF-1), insulin, and epidermal growth factor (EGF) are survival factors for density-inhibited quiescent BALB/c-3T3 murine fibroblasts. J. Cell. Physiol. 143:494-500.

19. Tamm, I., T. Kikuchi, and A. Zychlinsky. 1991. Acidic and basic fibroblast growth factors are survival factors with distinctive activity in quiescent BALB/c 3T3 murine fibroblasts. Proc. Natl. Acad. Sci. USA. 88:3372-3376.

20. Boobis, A. R., D. J. Fawthrop, and D. S. Davies. 1989. Mechanisms of cell death. Trends Pharmacol. Sci. 10:275-280.

21. Wyllie, A. H., J. F. R. Kerr, and A. R. Currie. 1980. Cell death: the significance of apoptosis. Int. Rev. Cytol. 68:251-305.

22. Wyllie, A. H. 1987. Cell death. Int. Rev. Cytol. 17(Suppl.):755-785.

23. West, N. B., R. L. Norman, B. Sondow, and R. M. Brenner. 1978. Hormonal control of nuclear estradiol receptor content and the luminal epithelium in the uterus of the golden hamster. Endocrinology. 103:1732-1741.

24. Cate, R. L., R. J. Mattaliano, C. Hession, R. Tizard, N. M. Farber, A. Cheung, E. G. Ninsa, A. Z. Frey, D. J. Gash, E. P. Chow, et al. 1986. Isolation of the bovine and human genes for Mullerian inhibiting substance and expression of the human gene in animal cells. Cell. 45:685-698.

25. Rotello, R., R. C. Lieberman, A. F. Purchio, and L. E. Gerschenson. 1991. Coordinated regulation of apoptosis and cell proliferation by transforming growth factor $\beta 1$ in cultured uterine epithelial cells. Proc. Natl. Acad. Sci. USA. 88:3412-3415.

26. Laster, S. M., J. G. Wood, and L. R. Gooding. 1988. Tumor necrosis factor can induce both apoptotic and necrotic forms of cell lysis. J. Immunol. 141:2629-2634.

27. Rosenblum, M. G., and N. J. Donato. 1989. Tumor necrosis factor $\alpha$ : a multifaceted peptide hormone. Crit. Rev. Immunol. 9:21-44.

28. Martinainen, P., N. Kuprianou, R. W. Tucker, and J. T. Isaacs. 1991. Programmed cell death of non-proliferating androgen-independent prostatic cancer cells. Cancer Res. 51:4693-4700.

29. Williams, G. T., C. A. Smith, E. Spooner, T. M. Dexter, and D. R. Taylor. 1990. Haemopoietic colony stimulating factors promote cell survival by suppressing apoptosis. Nature (Lond.). 343:76-79.

30. Yonish-Reuach, E., D. Resnitzky, J. Lotem, L. Sachs, A. Kumchi, and M. Oren. 1991. Wild-type p53 induces apoptosis of myeloid leukaemic cells that is inhibited by interleukin-6. Nature (Lond.). 352:345-347.

31. Sabourin, L. A., and R. G. Hawley. 1990. Suppression of programmed death and $\mathrm{G}_{1}$ arrest in B-cell hybridomas by interleukin-6. J. Cell. Physiol. 145:564-574.

32. McConkey, D. J., P. Hartzell, P. Nicotera, and S. Orrenius. 1989. Calcium-activated DNA fragmentation kills immature thymocytes. FASEB (Fed. Am. Soc. Exp. Biol.) J. 3:1843-1849.

33. Lotem, J., E. J. Cragoe, Jr., and L. Sachs. 1991. Reserve from programmed cell death in leukemic and normal myeloid cells. Blood. 78:953-960.

34. Askew, D. S., R. A. Ahmun, B. C. Simmons, and J. L. Cleveland. 1991. Constitutive c-myc expression in an IL-3-dependent myeloid cell line suppresses cell cycle arrest and accelerates apoptosis. Oncogene. 6:1915-1922.

35. Evans, G. I., A. H. Wyllie, C. S. Gilbert, T. D. Littlewood, H. Land, M Brooks, C. M. Waters, L. Z. Penn, and D. C. Hancock. 1992. Induction of apoptosis in fibroblasts by c-myc protein. Cell. 69:119-128.

36. Shi, Y., J. M. Glynn, L. J. Guilbert, T. G. Cotter, R. P. Bissonnettee, and D. R. Green. 1992. Role for c-myc in activation-induced apoptotic cell death T cell hybridomas. Science (Wash. DC). 257:212-214.

37. Henderson, S., M. Rowe, C. Gregory, D. Croom-Carter, F. Wang, R. Longnecker, E. Kieff, and A. Rickinson. 1991. Induction of bcl-2 expression by Estein-Barr virus latent membrane protein 1 protects infected B cells from programmed cell death. Cell. 65:1107-1115.

38. Liu, Y. J., D. Y. Mason, G. D. Johnson, S. Abbot, C. D. Gregory, D. L. Hardie, J. Gordon, and I. C. MacLennan. 1991. Germinal center cells express bcl-2 protein after activation by signals which prevent their entry into apoptosis. Eur. J. Immunol. 8:1905-1910. 